\title{
Improving Resistance of Gravity Dam to Seismic Wave by Using Stepped Base
}

\author{
Asmaa Abdul Jabbar ${ }^{1, a}$, Raad H. Irzooki ${ }^{1, b}$, and Ahmed A. H. Al-Obaidi1 ${ }^{1, c}$ * \\ ${ }^{1}$ Deptartment of Civil Engineering, Tikrit University, Tikrit, Iraq

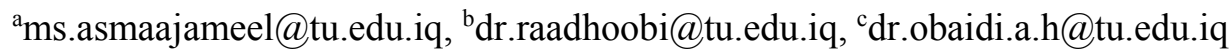

\begin{abstract}
This study analyzes the possible modes of the seismic wave for concrete gravity dams and the damage occurring in the body where two gravity dam sections are taken as a case study. Model (1) is a typical section of a gravity dam, while model (2) is a gravity dam section provided with specified steps at its base. The design of seismic waves included Operational Base Earthquake (OBE), Maximum Design Earthquake (MDE), and Maximum Credible Earthquake (MCE) levels. The dam body-foundation-reservoir water interaction system is analyzed by numerical analysis software (ABAQUS). The main conclusion shows that the gravity dam model's underground motion loadings have a noticeable increase in the displacement distribution within the first gravity dam body model, especially in the higher mode compared to the first model. The first model's Damage Index value was equal to 0.357 at the MCE wave, which does not appear in the second model. The time taken for the damage that occurs within a model (1) is faster than the model (2). Consequently, model (2) significantly reduces seismic waves with different intensity levels on the amount of damage transmission within the gravity dam body.
\end{abstract}

Keywords: Gravity dam; damage; mode; seismic; OBE; MDE, MCE.

\section{Introduction}

The concrete gravity dam may crack and slide, causing damage. Its strength and stiffness will decrease under earthquakes with a severity greater than moderate level. The continuum of damage is a valuable technique to effectively modeling the degradation in concrete dam's mechanical properties. Therefore, it is essential to search for gravity dam models that resist seismic waves' impact [1]. Operational Base Earthquake (OBE), Maximum Design Earthquake (MDE), and Maximum Credible Earthquake (MCE) are seismic earthquake ground movements for the design and evaluation of concrete hydraulic structures. OBE level seismic forces are known as unusual loads, whereas MDE and MCE seismic forces are regarded as extreme loads. Seismic earthquake loads must be unified with multiple loads for design purposes expected to be available during routine operations [2-5]. The damage starts from the heel within the gravity dam's body and then extends over the dam's upstream material and progresses to its downstream face [6-9]. Due to strong seismic waves, the energy dissipated inside the gravity dam's body is often within 3-5 seconds. Researchers have also found that when the interaction between (foundation - dam-reservoir) is considered, the damage at the heel tends to be greater than when the model only considers the interaction between (dam-foundation) or (damreservoir) [10,11]. Aldemir [13] indicates that MDE level analysis has expanded the lengths and widths of cracks. The width and length of the most severe crack reached $0.4 \mathrm{~mm}$ and $550 \mathrm{~mm}$, respectively. Also, increasing the measured Peak Ground Acceleration PGA would effectively increase the damage and cracks within the gravity dam body, as it decreases the resistance of the gravity dam to the seismic earthquakes by increasing the crack in it [12-18]. In addition, a researcher demonstrated that moderate and severe damage probabilities were $16 \%$ and $8 \%$ under the OBE level, respectively. In comparison, they were $53 \%$ and $29 \%$ under the MDE level and more than $90 \%$ under the MCE level [19].

Thus, as a result of the spread of the wave inside the dam body, seismic waves would affect the gravity dam and cause damage. Also, because of the hydrodynamic pressure effect, the gravity dam will slide over the foundation. The research's main objective is to eliminate the damage caused by sliding the gravity dam and decrease the impact of the seismic wave spreading within the gravity dam 
body. Also, it is required to demonstrate the effect of stepping within the gravity dam base, which is used to decrease seismic waves' influence within the gravity dam body. It also needs to compare the stepped base gravity dam model with the common gravity dam model used in hydraulic designs.

\section{Numerical Models of the Current Study}

Adopting two gravity dam models, the first model (M1), as shown in Figure 1, representing the common dam model in the designs of gravity dam. The second model (M2) is shown in Figure 2 as a solution for impact effect due to an earthquake using the stepped at the base of the gravity dam. They are taken to ensure a stronger connection between the base of the gravity dam and the rock's foundation to minimize the effects of earthquake sliding as much as possible.

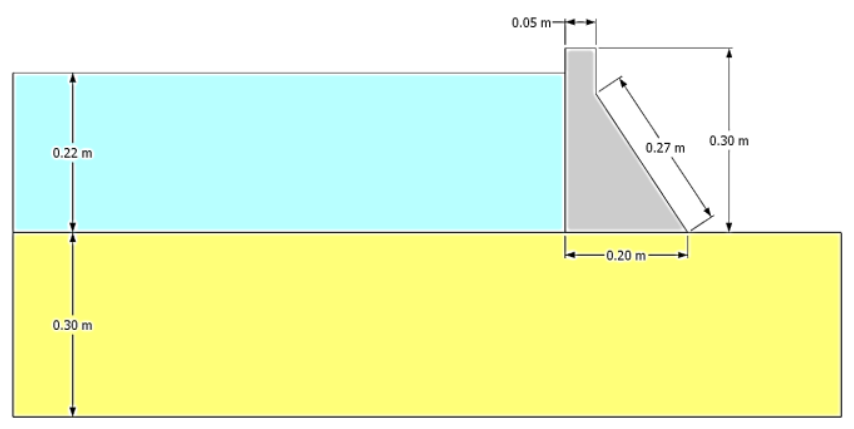

Figure 1. Model 1 (M1).

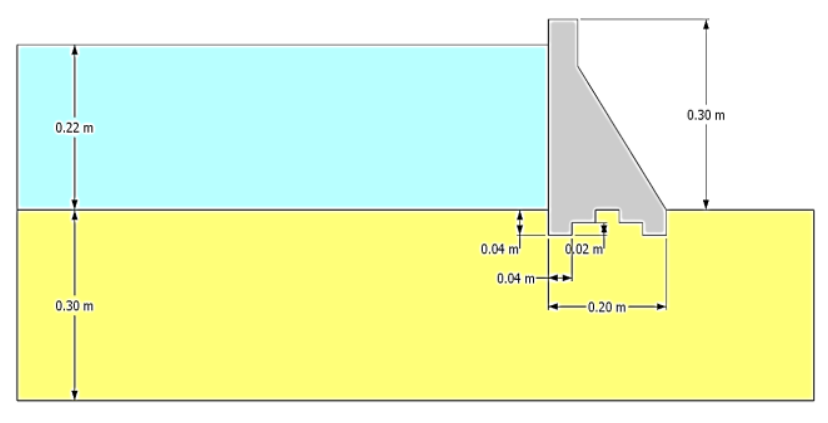

Figure 2. Model 2 (M2).

\section{Two-Dimensional Idealization}

The current practice of modeling concrete gravity dams follows a two-dimensional approach under the plane strain assumption. This model (the plane strain) condition for the foundation and dam has been used by [20-23] to study the gravity dam's earthquake response.

Finite Element Model of the System. ABAQUS program was used to model the concrete gravity dam-Foundation-Reservoir system. The model of finite elements was divided into convenient finite element sizes. The size and shape of components are vital, and some basic specifications have been developed to make it simpler to construct well-functioning components. Quad and Tri elements are the two most common forms of two-dimensional elements. Tri elements are characterized into three nodes and contain just one integration point, while quads are composed of four nodes and contain four integration points. Quad elements are, however, more accurate and are to be preferred [24]. So only quad elements are used in our models, as shown in Figure 3. CPS4R components were used to model the gravity dam and foundation (4-node bilinear plane strain solid continuum elements with reduced integration and hourglass control). AC2D4 elements are used to model the reservoir (4-node bilinear acoustic elements). Also, such as at the bottom and lateral sides of the foundation, as shown in Figure 4, CINPE4 infinite elements were used (4-node bilinear plane strain rigid continuum infinite elements) to prevent seismic reflection waves back to the gravity dam.

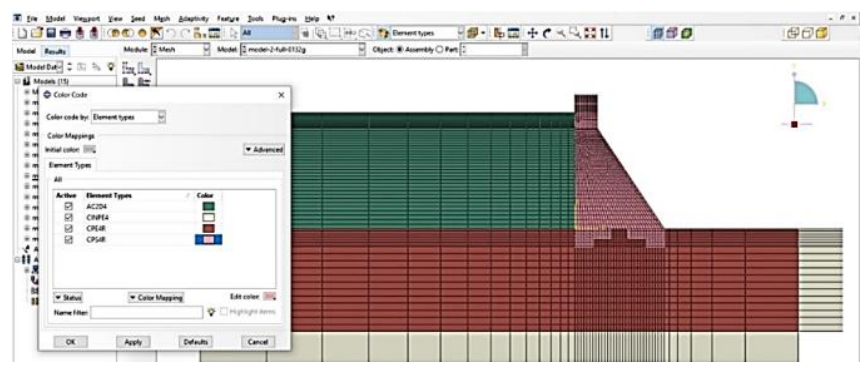

Figure 3. Element Type and Mesh for models (M2).

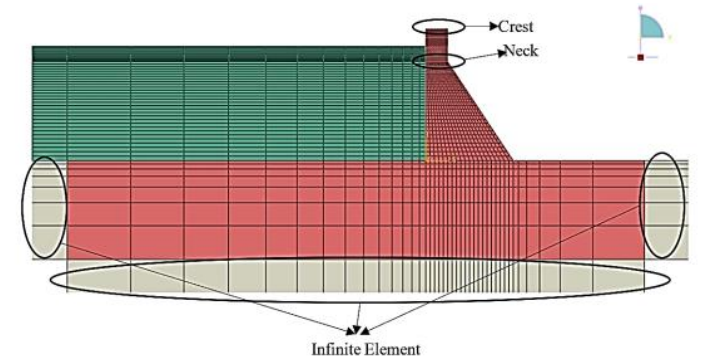

Figure 4. The infinite element for models. 
Contact Interfaces/ Boundary Conditions/ Applied Load and Steps. If the interaction between the two discrete surfaces is considered, more practical numerical results can be obtained by identifying interaction couples between these surfaces. The two-dimensional finite element model of gravity dam- reservoir -foundation was modeled for this reason, and various elements of interaction between separate surfaces were considered, as shown in Figure 5. Firstly, sliding contact with zero friction elements was defined between the gravity dam body and the reservoir. Tied communication was introduced for the reservoir-foundation interface, except near the dam's upstream face, where sliding contact with zero friction was used to maintain the reservoir load during the gravity dam sliding. Combining contact elements with a tension-shear failure criterion between dam and foundation rock was considered. The finite element code suggests the interface surface is broken when the following criteria is fulfilled, see Eq.1:

$$
\left(\frac{\left|\sigma_{\mathrm{n}}\right|}{\mathrm{NFLS}}\right)^{2}+\left(\frac{\left|\sigma_{\mathrm{S}}\right|}{\mathrm{SFLS}}\right)^{2} \geq 1
$$

where $\sigma_{n}$ and $\sigma_{S}$ are the normal and shear stress, respectively, NFLS is the tensile strength, and SFLS is the cohesion. The tensile-compressive and shear stresses are distributed at the contact stage if the failure condition is not met. In the case of normal compression stress, the first term of Eq. 1 is not considered, and only cohesion is considered. Moreover, due to breaking contact, no resistance is mobilized by friction. Once the failure criteria are met, only the friction adds to the interaction resistance [25]. In addition, non-reflective limits were applied to the end of the model reservoir to accommodate the radiation damping and dissipate the energy stored in the foundation because of its finite length (i.e., to simulate infinite behavior).

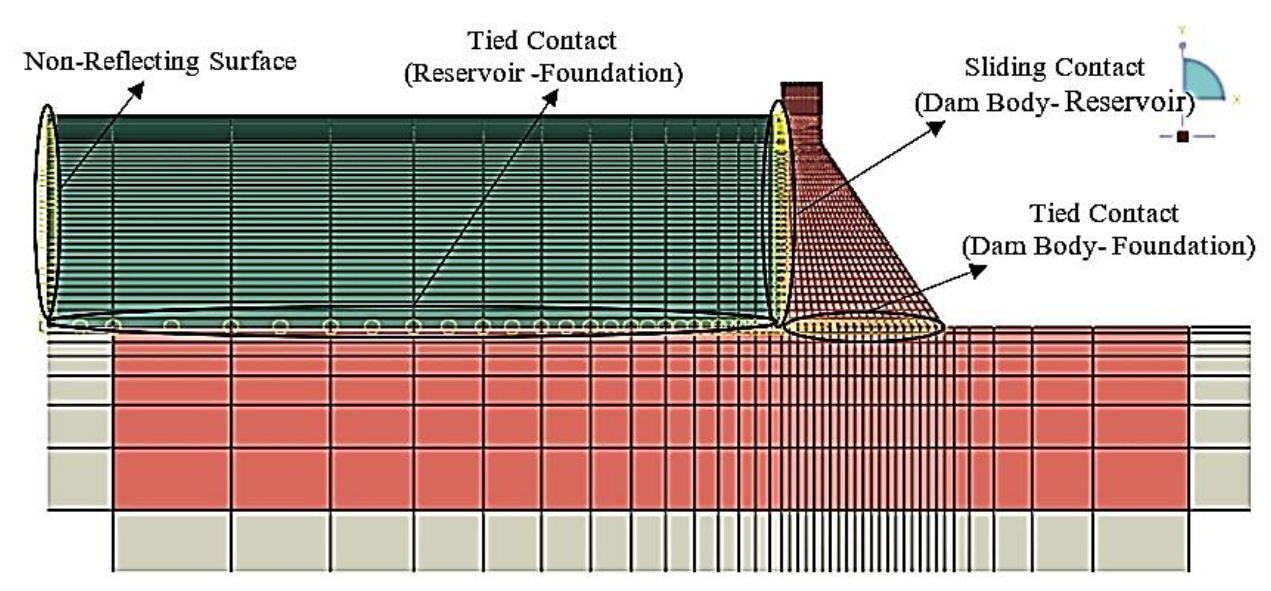

Figure 5. Interaction surfaces.

Often, applied loads include the self-weight of the gravity dam, hydrostatic pressure, uplift pressure, hydrodynamic pressure, and seismic forces in order to achieve the nonlinear behavior of concrete gravity dams are exposed to seismic sequences through time history. In the dynamic studies of the structure, the gravity dam's static solutions due to its gravity loads and hydrostatic loads are taken as initial conditions, as shown in Figure 6. Where Fig.7 shows the design of seismic waves. Three different earthquake levels were chosen in the design, OBE, MDE, and MCE seismic level, and peak ground acceleration (PGA) equal to $0.112 \mathrm{~g}, 0.16 \mathrm{~g}$, and $0.33 \mathrm{~g}$, respectively. The original time histories (Densmore Ave earthquake) were choosing as scaling concerning [28]. Depending upon the loading step, the boundary conditions were different. Asymmetric boundary condition was introduced in the bottom and downstream-upstream faces during the static process, where the normal displacements equal to zero to simulate the model's limitations. Symmetric boundary conditions were eliminated in the dynamic phase, and the reactions obtained from the dynamic relaxation phase were also added to the equilibrium boundary faces. 


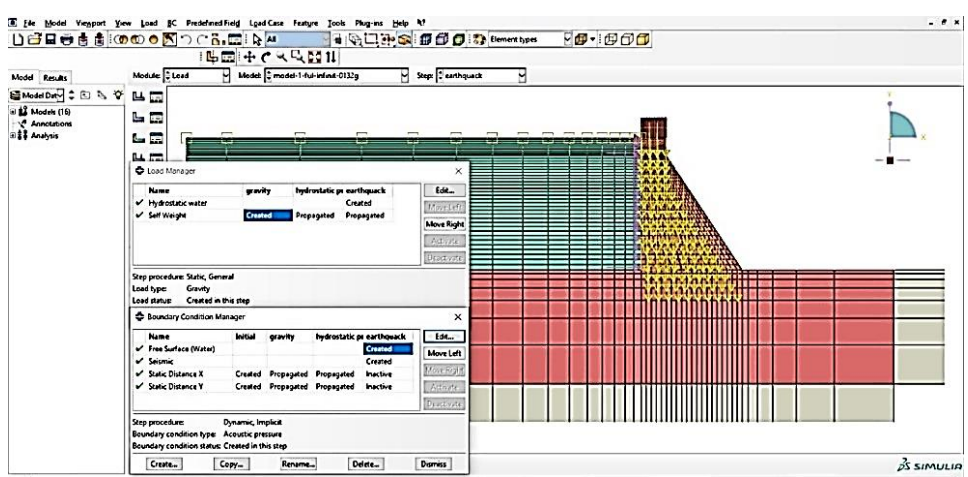

Figure 6. Applied load and boundary condition.

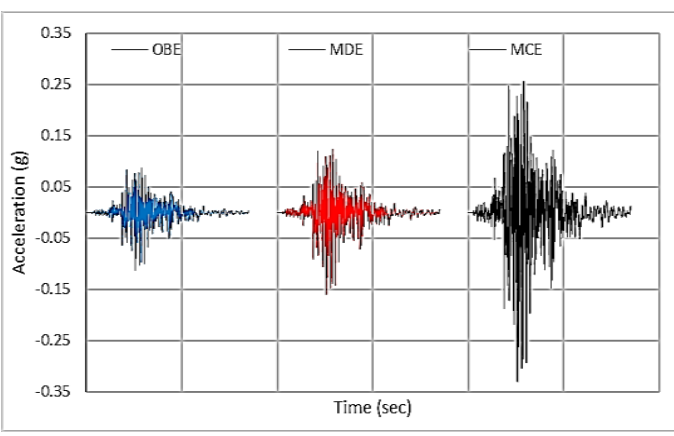

Figure 7. Site-Specific Design Ground Motions [28].

\section{Results and Discussion}

Frequencies and Mode Shapes. Natural frequency, time period, and mode shape were specified for the gravity dam models based on the Abaqus software. The iterations needed in the model analysis process consist of selecting the suitable spectrum of ground motion response, applying a dynamic analysis technique to a structure mathematical model, combining the response of a sufficient number of modes to ensure $80 \%$ of the structure mass, scaling the outcomes to ensure conformity with the technique of static lateral force [25]. Table 1 summarizes these results. For both gravity dam models, the percentage of the model masses represents approximately more than $90 \%$ of the system's total mass, and the gravity dam's behavior under seismic load is appropriately described for six modes in the current study. The gravity dam (M1 and M2) mode shapes are shown in Figure 8. At all modes for $\mathrm{M} 2$, there is a noticeable increase in natural frequency as compared to M1, this means that the stiffness of M2 is greater than M1. The amount of increase in natural frequency for M2 is between 18.5-37.2\% compared to M1 due to an increase in stiffness of M2 even with increasing the mass of it. Where, as mentioned by [28] with the Eq.2:

$f=\frac{1}{2 \pi} \sqrt{\frac{k}{m}}$

Where $\mathrm{f}, \mathrm{k}$, and $\mathrm{m}$ are frequency, stiffness, and mass structure, respectively. Also, in these modes, a noticeable increase in the displacement distribution inside the first gravity dam body model is shown by contour lines compared to the second model, especially in the higher mode.

Table 1. Frequency, time period, and Mass at Each Mode, for M1\&M2.

\begin{tabular}{|c|c|c|c|c|c|c|c|}
\hline \multicolumn{4}{|c|}{ Model 1 } & \multicolumn{4}{c|}{ Model 2 } \\
\hline Mode & Frequencies (Hz) & Period (s) & Mass (\%) & Mode & Frequencies (Hz) & Period (s) & Mass (\%) \\
\hline 1 & 155.41 & 0.0064 & 37.88 & 1 & 190.73 & 0.0052 & 37.60 \\
\hline 2 & 392.40 & 0.0025 & 26.27 & 2 & 481.44 & 0.0021 & 24.17 \\
\hline 3 & 522.62 & 0.0019 & 9.60 & 3 & 642.82 & 0.0016 & 9.93 \\
\hline 4 & 753.06 & 0.0013 & 12.20 & 4 & 933.86 & 0.0011 & 11.71 \\
\hline 5 & 1032.66 & 0.0010 & 0.0001 & 5 & 1492.76 & 0.0007 & 6.92 \\
\hline 6 & 1127.54 & 0.0009 & 7.31 & 6 & 1795.50 & 0.0006 & 1.59 \\
\hline Total & & & 93.28 & & & & 91.92 \\
\hline
\end{tabular}

Figures 9 to 11 represent the values of the damages resulting in the gravity dam body as a consequence of the three design waves OBE, MDE, and MCE. 


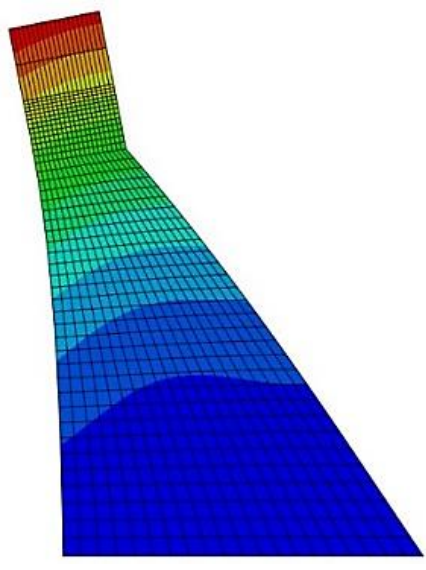

a. $\quad$ Mode 1 (M1).

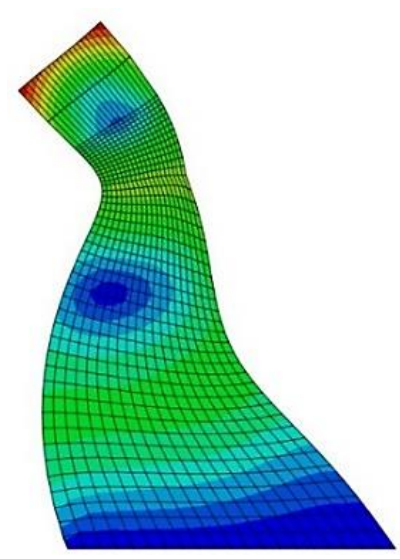

d. $\quad$ Mode 4 (M1).

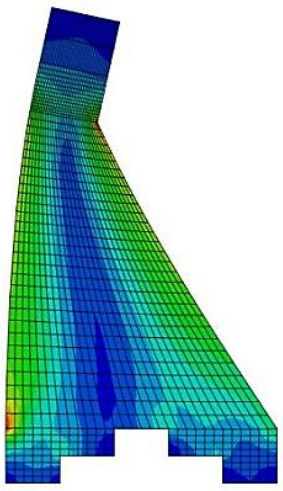

g. Mode 1 (M2).

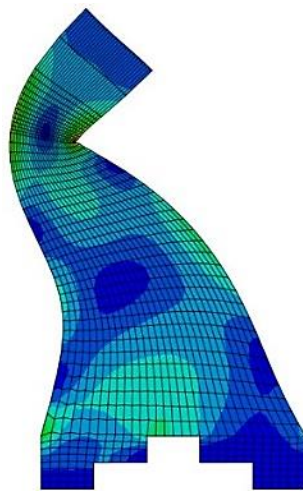

j. Mode 4 (M2).

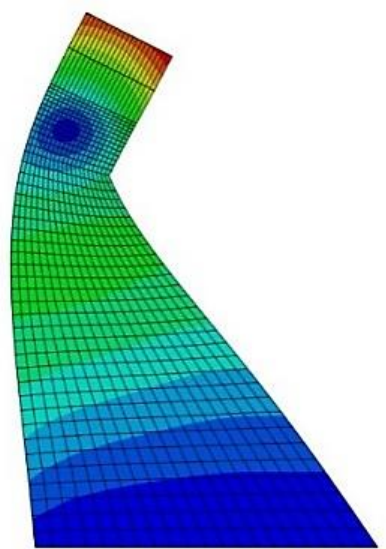

b. $\quad$ Mode 2 (M1).

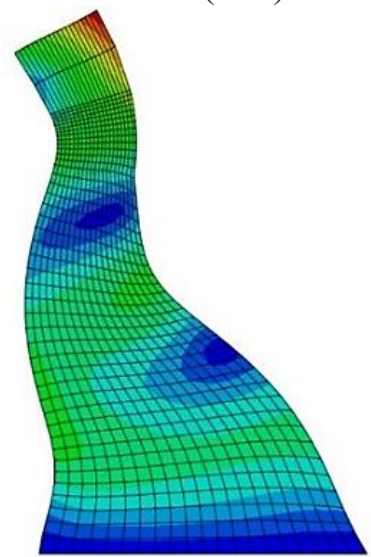

e. $\quad$ Mode 5 (M1).

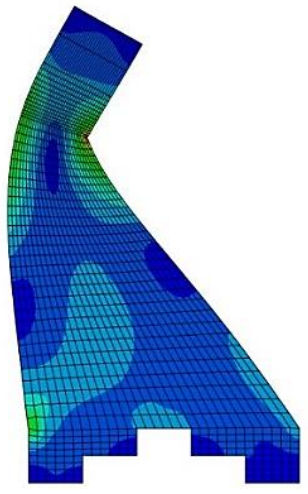

h. $\quad$ Mode 2 (M2).

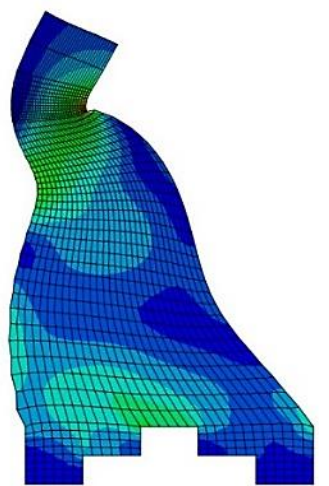

k. Mode 5 (M2).

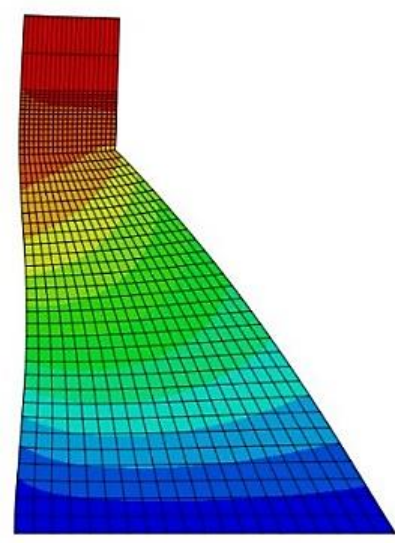

c. Mode 3 (M1).

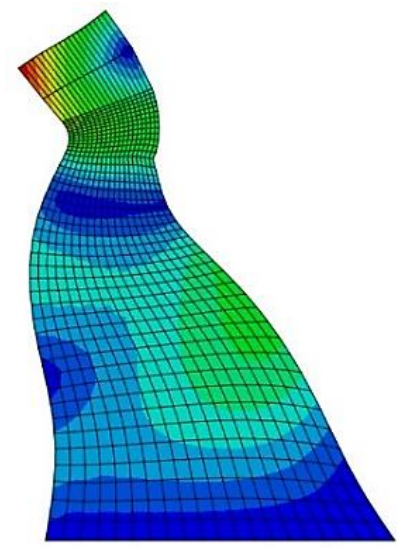

f. $\quad$ Mode 6 (M1).

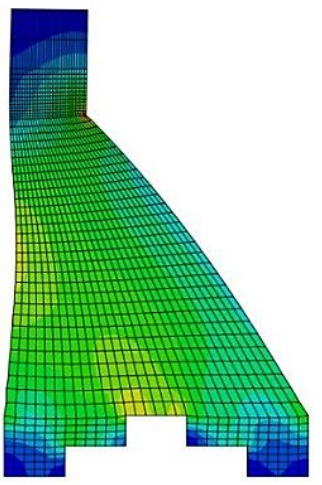

i. $\quad$ Mode 3 (M2).

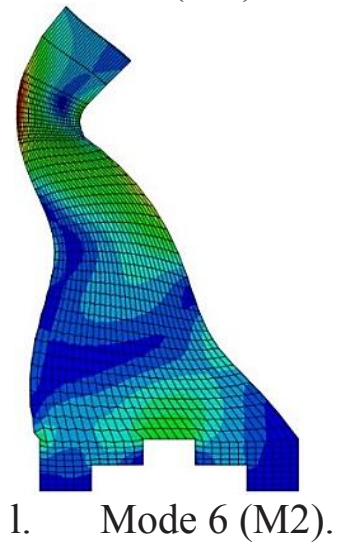

1. Mode $6(\mathrm{M} 2)$.

Figure 8. Modes shape for model 1 (M1) and model 2 (M2). 


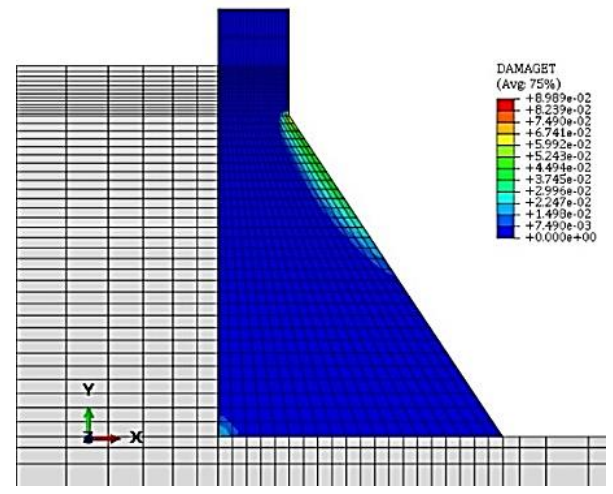

a. Model 1.

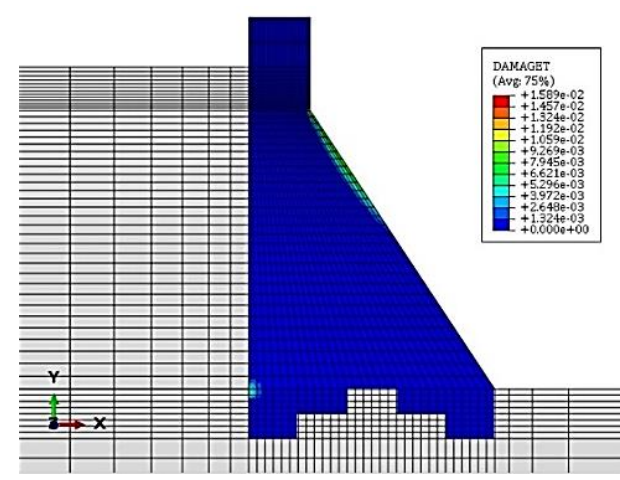

b. Model 2.

Figure 9. Damage at gravity dam body at OBE.

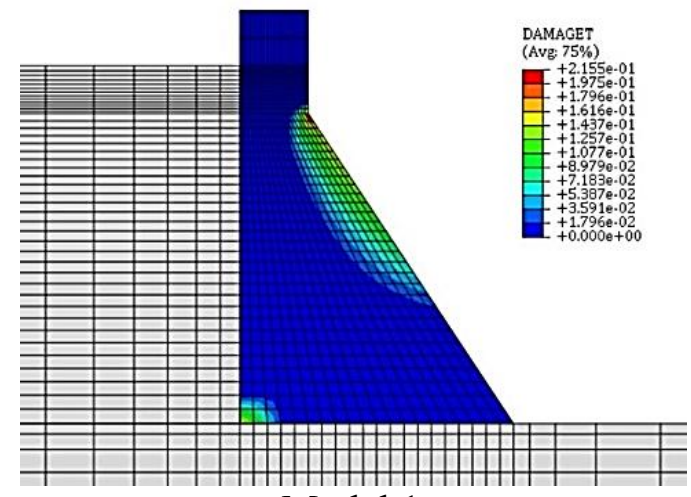

a. Model 1.

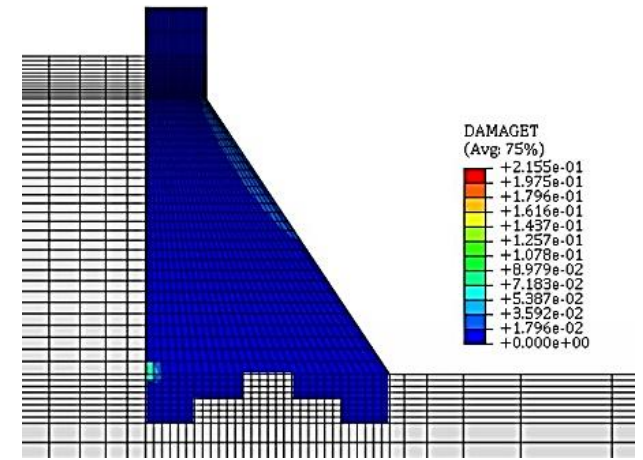

b. Model 2.

Figure 10. Damage at gravity dam body at MDE.

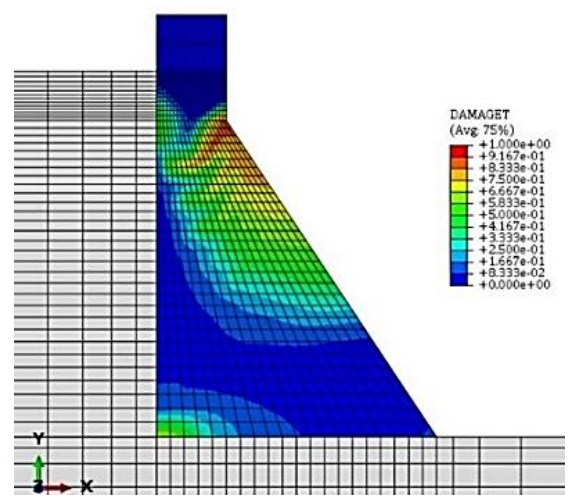

a. Model 1.

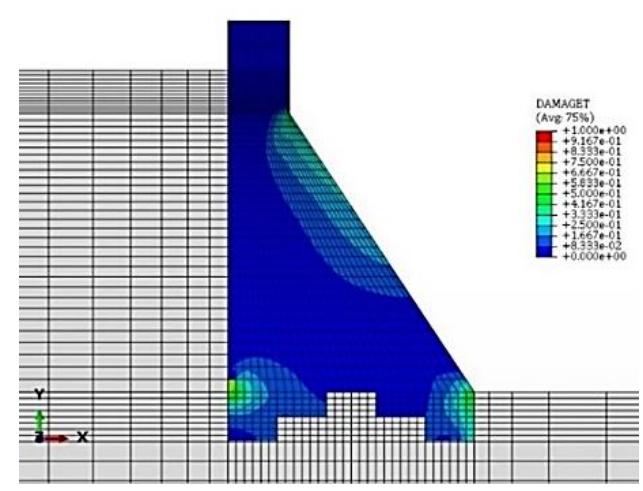

b. Model 2.

Fig.11. Damage at Gravity Dam Body at MCE.

Gravity Dam Damage. Tensile damage is assessed using DAMAGET in order to evaluate damage criteria in the gravity dam model. Accessible in the ABAQUS program, values vary from 0 to 1 , where 0 is intact content and 1 is total damage. Models of seismic design waves are used as an indicator to explain the actions attributed to tensile disruption occurring in the gravity dam body. It was found that the damage was distributed within the gravity dam body at two levels of it represented by the gravity dam base (which is the most significant just at the heel portion due to the simultaneous influence of the hydrostatic and hydrodynamic pressures at the upstream, and the uplift pressure under the gravity dam body). Also, at the narrowing area for the top of the gravity dam (the dam neck), which forms from downstream face to upstream face of gravity dam. Compared to the associated signal mainshocks, the standard seismic series needs an improved ability to bear the nonlinear requirements (i.e., damage residual displacement accumulation and damage dissipated energy). It is also evident that the design seismic waves influenced the M1 significantly on the accumulated damages noticeable at the MCE wave. This indicates a substantial weakening in the gravity dam's 
strength, which is shown by a crack that extends entirely over the upper part (at the neck), which has a measurement of magnitude known as Index of local damage (DI). DI is defined as the ratio of the length of a cracking path to the cross-section of the gravity dam's total length. This local DI can be defined as shown in Eq.3:

$$
\mathrm{DI}_{\mathrm{Li}}=\frac{\mathrm{L}_{\mathrm{Di}}}{\mathrm{L}_{\mathrm{i}}}
$$

Where, $\mathrm{DI}_{\mathrm{Li}}$ is Index of local damage for crack path $\mathrm{i}, \mathrm{L}_{\mathrm{i}}$ is the total length to which crack path $\mathrm{i}$ projected to make. whereas, $\mathrm{L}_{\mathrm{Di}}$ is the actual length of crack path $\mathrm{i}$ [27]. Therefore, the results show that at the MCE wave, the DI value of the M1 is equal to 0.357 , and this indicator did not appear in the rest of the M1 and M2 cases due to the absence of crack resulting from complete element damage. Figures 12 to 15 indicate the amount of damage that occurs at the gravity dam body at both heel and neck of models for design seismic waves OBE, MDE, and MCE. These figures display the change in the amount of damage as time passes and reach a certain limit, and then the amount of the increase in damage will stop at those points. Thus, increasing seismic wave intensity would increase the amount of damage in the gravity dam body. Increasing the seismic index from OBE - MDE - MCE increment would increase the amount of damage at a rate of approximately $80.6 \%$ in the heel and $67.5 \%$ in the neck for M1. For M2, the damage increases occur as the increases from OBE-MDEMCE increment approximately $86.6 \%$ and $81.5 \%$ for the element under the heel and neck. Due to step foundation for gravity dam used at the base of $\mathrm{M} 2$, which contributed greatly to reducing the vibration transmitted through the gravity dam body, reducing the damage caused by tension.

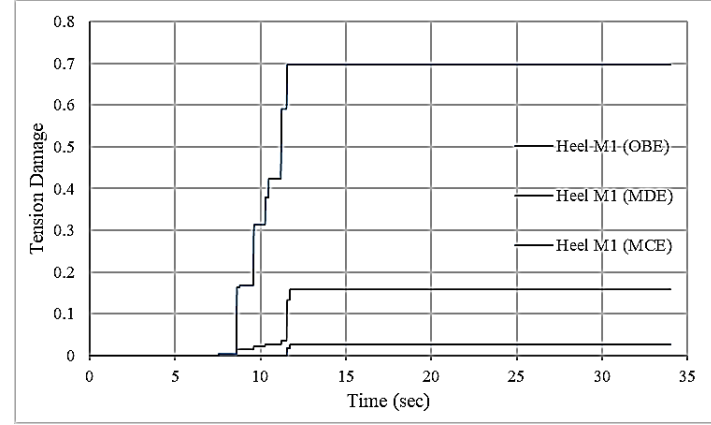

Fig.12. Damage Amount at Heel for M1.

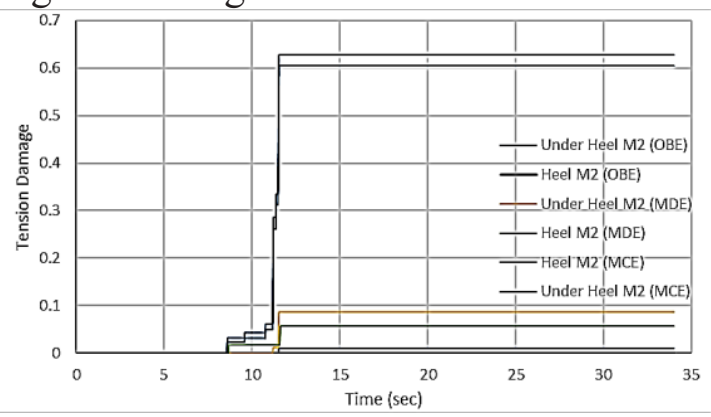

Figure 14. Damage Amount at Heel and Under Heel for M2.

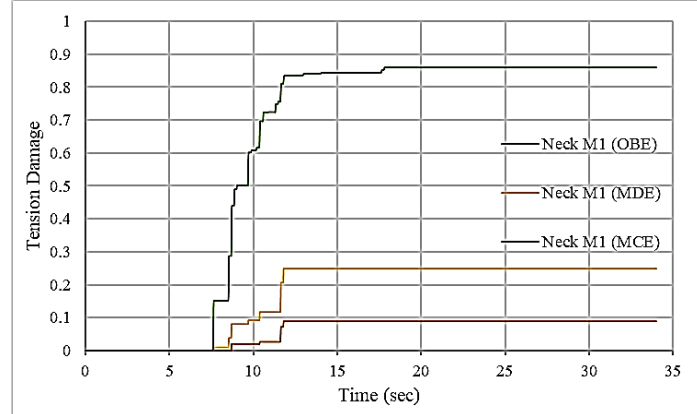

Fig.13. Damage Amount at Neck for M1.

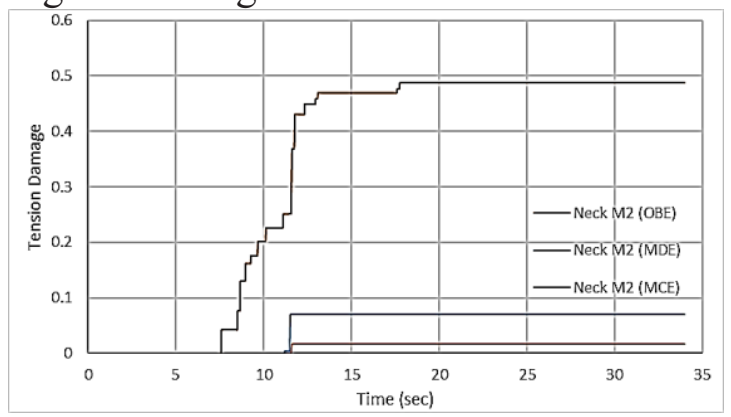

Figure 15. Damage Amount at Neck for M2.

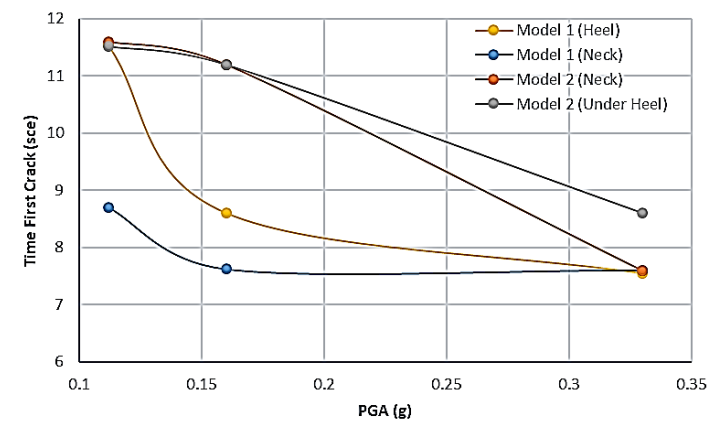

Figure 16. Time for First Crack at M1 and M2. 
Although the time required for the first damage to appear within the gravity dam structure resulting from energy dispersion inside the model is shown in Fig.16. It is obvious from the above figure that the time needed for damage to occur inside M1 (at the neck and heel) is faster than the M2. Due to the Amplification Factor (A.F.) for M1 is higher and, consequently, increases the dam vibration, thus generating damaging cracks.

\section{Conclusions}

The following conclusions have been reached:

- As a result of an increase in M2 stiffness, the assessment in natural frequency of M2 was between 18.5 - $37.2 \%$ compared to M1.

- Compared to M2, a noticeable increase was remarked in the displacement distribution within the M1, especially in the higher mode.

- It is also clear that the seismic wave design significantly influenced M1 on the cumulative damages noticeable on the MCE hit. This suggests a significant weakening of the gravity dam strength, which is seen by a crack spreading entirely over the upper part (at the neck).

- The DI value of the M1 model is equal to 0.357 at the MCE wave, and this indicator did not appear on the M2 model due to the absence of crack resulting from complete damage to the element.

- Increasing the OBE-MDE-MCE seismic index may raise the amount of damage at a rate of about $80.6 \%$ in the heel and $67.5 \%$ in the neck for M1, and $86.6 \%, 81.5 \%$ for the M2 model under the heel and neck section, respectively.

- Compared to M2, the time taken for damage to occur within M1 (at the neck and heel) is faster. This is because the Amplification Factor (A.F.) for M1 is higher and hence increases the vibration of the dam that causing damaging cracks.

\section{References}

[1] Jamel, A.A.J., Irzooki, R.H. and Al-Obaidi, A.A., 2020. Behavior of Gravity Dams Affected by Earthquakes as A Review. Solid State Technology, 63(5), pp.8317-8338.

[2] Ghanaat, Y. and Chudgar, A.K., 2007. Seismic Design and Evaluation of Concrete Dams-An Engineering Manual.

[3] Hariri-Ardebili, M.A., Heshmati, M., Boodagh, P. and Salamon, J.W., 2019. Probabilistic Identification of Seismic Response Mechanism in a Class of Similar Arch Dams. Infrastructures, 4(3), p.44.

[4] Wagle D., 2010. Earthquake Response of Concrete Gravity Dams. M.Sc. Thesis, Swinburne University of Technology.

[5] US Army Corps of Engineers, 2007. Earthquake design and evaluation of concrete hydraulic structures engineer, Washington.

[6] Zappitelli, M.P., Villa, E.I., Fernández-Sáez, J. and Rocco, C., 2014. Cracking Development Prediction in Concrete Gravity Dams using Concrete Damage Plasticity Model. Mecánica Computacional, 33(14), pp.909-921.

[7] Wang, M., Chen, J., Wei, H., Song, B. and Xiao, W., 2019. Investigation on seismic damage model test of a high concrete gravity dam based on application of FBG strain sensor. Complexity, 2019.

[8] Das, R. and Cleary, P.W., 2013. A mesh-free approach for fracture modelling of gravity dams under earthquake. International Journal of Fracture, 179(1-2), pp.9-33.

[9] Zeidan B.A. and Seleemah A., 2018. Seismic stability analysis of concrete gravity dams. Conference ICOLD, at Vienna, 1-7/7/2018.

[10] Mandal, K.K. and Maity, D., 2018. Transient response of concrete gravity dam considering damreservoir-foundation interaction. Journal of Earthquake Engineering, 22(2), pp.211-233. 
[11]Zeydan, A.B., 2013, April. Seismic Dam-Reservoir Interaction of Concrete Gravity Dams. In 9th European Club Symposium (pp. 10-12).

[12] Yamaguchi, Y., Hall, R., Sasaki, T., Matheu, E., Kanenawa, K.I., Chudgar, A. and Yule, D., 2004, August. Seismic performance evaluation of concrete gravity dams. In Proceedings of the 13th World Conference on Earthquake Engineering.

[13] Aldemir, A., Binici, B., Canbay, E.R.D.E.M., Kurc, O. and Arici, Y.A.L.I.N., 2014. Pseudo dynamic test results of a concrete gravity dam. Tenth U.S. National Conference on Earthquake Engineering, Anchorage, Alaska.

[14] Banerjee, A., Paul, D.K. and Acharyya, A., 2015. Optimization and safety evaluation of concrete gravity dam section. KSCE Journal of Civil Engineering, 19(6), pp.1612-1619.

[15] Wang, M., Chen, J., Fan, S. and Lv, S., 2014. Experimental study on high gravity dam strengthened with reinforcement for seismic resistance on shaking table. Structural Engineering and Mechanics, 51(4), pp.663-683.

[16]Zheng, X. and Hao, J., 2019, November. Research on Seismic Assessment of Gravity Dam Based on Performance Analysis. In IOP Conference Series: Earth and Environmental Science (Vol. 376, No. 1, p. 012036). IOP Publishing.

[17] Mohsin, A.Z., Omran, H.A. and Al-Shukur, A.H.K., 2015. Dynamic response of concrete gravity dam on random soil. International Journal of Civil Engineering and Technology, 6(11), pp.2131 .

[18] Shuai Li, Tanzim M., Roger P., Shahria A., CSCE M., and Anas S., 2019. Comparative seismic performance of dams in canada and china using numerical analysis and shake table testing. ICOLD 2019 Annual Meeting/Symposium, Ottawa, Canada.

[19] Ganji, H.T., Alembagheri, M. and Khaneghahi, M.H., 2019. Evaluation of seismic reliability of gravity dam-reservoirinhomogeneous foundation coupled system. Frontiers of Structural and Civil Engineering, 13(3), pp.701-715.

[20] Ali, M.H., Alam, M.R., Haque, M.N. and Alam, M.J., 2012. Comparison of design and analysis of concrete gravity dam. Natural Resources, 3, pp.18-28.

[21] Huang J., 2011. Seismic response evaluation of concrete gravity dams subjected to spatially varying earthquake ground motions. Ph.D., Thesis, Drexel University, Philadelphia,

[22] Chen, D.H., Yang, Z.H., Wang, M. and Xie, J.H., 2019. Seismic performance and failure modes of the Jin'anqiao concrete gravity dam based on incremental dynamic analysis. Engineering Failure Analysis, 100, pp.227-244.

[23] Ghallab, A., 2020. Simulation of Cracking in High Concrete Gravity Dam Using the Extended Finite Elements by ABAQUS. American Journal of Mechanics and Applications, 8(1), pp.7-15.

[24]Zeidan, B.A., 2014. Design and analysis of concrete gravity dam. Article Review. Tanta University.

[25] Segura, R.L., Bernier, C., Durand, C. and Paultre, P., 2019. Modelling and characterizing a concrete gravity dam for fragility analysis. Infrastructures, 4(4), p.62.

[26] IBC-CODE, 2018. International Building Code. USA.

[27] Al-Qaisi Z. A. M., 2016. Optimal design of concrete gravity dams of random soil, Ph.D. Thesis, University of Technology, Baghdad, Iraq.

[28] Wang, G., Wang, Y., Lu, W., Yan, P., Zhou, W. and Chen, M., 2017. Damage demand assessment of mainshock-damaged concrete gravity dams subjected to aftershocks. Soil Dynamics and Earthquake Engineering, 98, pp.141-154.

[29] Aldemir A., and Binici B., 2017. Seismic Performance evaluation of concrete gravity dams by using pseudo dynamic testing and simulations. Australian Earthquake Engineering Society Conference. 